\title{
EDITORIAL
}

\section{ESTADO, CIÊNCIA E PANDEMIA}

\section{Edson Aparecida de Araújo Querido Oliveira ${ }^{1}$}

O enfrentamento da pandemia do COVID 19 tem ocupado posição central no debate acerca das políticas públicas. $O$ rápido desenvolvimento de vacinas e novos fármacos para tratar a infecção e suas consequências, indica o potencial de aprimoramento dos recursos a serviço do bem-estar humano. Porém, tal conquista é acompanhada por contrastes quanto à disponibilidade e acesso. As vacinas têm distribuição desigual em âmbito global, replicando as assimetrias sociais e econômicas entre os Estados e suas respectivas populações. Os países desenvolvidos concentram os recursos necessários ao enfrentamento da COVID, em detrimento das demais nações. Situação inaceitável, tanto sob o prisma dos direitos humanos quanto sanitário, pois permanece a circulação internacional do vírus e respectiva ameaça as sociedades contemporâneas.

Entre os contrastes e desafios pertinentes à pandemia, destaca-se o papel do Estado e sua centralidade para a articulação e efetivação de ações para o enfrentamento da emergência sanitária. Políticas públicas centradas na contenção da propagação do vírus e obtenção de vacinas tem propiciado a países como Nova Zelândia e Israel, por exemplo, a possibilidade de relaxar as medidas restritivas impostas as respectivas populações. Em comum, os casos bem sucedidos revelam decisões rápidas e articuladas, combinando prevenção sanitária, assistência à população e busca de vacinas.

A necessidade de recuperação da capacidade de investimento e articulação pública do Estado evidencia os limites do setor privado em desenvolver ações e recursos aptos a promover o bem-estar da população, para além da reprodução do capital e do acesso limitado aos grupos sociais com renda mais elevada. Após décadas de hegemonia neoliberal, com o desmantelamento das capacidades estatais e a ampliação das assimetrias sociais, dissecadas por Thomas Piketty, a atual conjuntura evidencia premência do desenvolvimento associado ao planejamento e execução de políticas públicas relacionadas à sustentabilidade social, ambiental e econômica. As pesquisas realizadas sobre a pandemia indicam que a vulnerabilidade ao COVID 19 é maior exatamente nos grupos sociais mais fragilizados perante as assimetrias sociais e econômicas.

Propiciar a incorporação dos resultados das pesquisas realizadas na área do desenvolvimento regional é um dos meios para promover políticas públicas necessárias ao enfrentamento das consequências da pandemia do COVID 19, bem como das assimetrias presentes no Brasil. A ausência de planejamento e ações de desenvolvimento condizentes com os desafios nacionais relegará o país à dependência permanente de recursos externos. Exemplo dos efeitos nefastos sobre a população nacional do abandono da soberania sobre as condições de desenvolvimento é a dependências da importação de insumos para o enfrentamento da pandemia, desde equipamentos de proteção individual a medicamentos e recursos para produção de vacinas.

Recuperar a capacidade de produzir tecnologia nacional nas diversas áreas do saber e associá-las a políticas públicas corresponde a retomar a capacidade de desenvolvimento nacional,

\footnotetext{
${ }^{1}$ Editor Chefe da G \& DR. Economista, Mestre em Economia pela Pontifícia Universidade Católica de São Paulo (PUCSP)Doutor em Engenharia Aeronáutica e Mecânica pelo Instituto Tecnológico de Aeronáutica (ITA). Pós-Doutor em Gestão da Inovação Tecnológica pelo Instituto Tecnológico de Aeronáutica (ITA). Coordenador Geral e Professor do |Programa de Pósgraduação em Gestão e Desenvolvimento Regional da Universidade de Taubaté (UNITAU). E-mail: edsonaaqo@gmail.com.
} 
condição que somente será efetiva com a elaboração e preservação de uma política de Estado soberana, orientada por interesses e objetivos nacionais. Tal premissa possibilita buscar o desenvolvimento nacional com o efetivo combate as assimetrias sociais, necessariamente associado à preservação da democracia, da transparência das políticas públicas e do refutar do negacionismo científico e subserviência a ideologias autoritárias, que buscam reviver um passado nefasto e ditatorial. Assim, o campo de saber resultante das investigações sobre o desenvolvimento regional tem função estratégica para o alcance destas premissas. Os artigos da atual edição associam-se as publicações anteriores para fomentar e contribuir com o debate necessário para o desenvolvimento nacional.

Esta obra está licenciada com uma Licença Creative Commons Atribuição 4.0 Internacional. 